\title{
Grid-connected Control Strategy of PV Battery-energy Storage Hybrid Power System with Electric vehicle
}

\author{
Haiping Liang, Yan Li, Yingpei Liu, Jia He, Hanyang Cui \\ School of Electrical and Electronic Engineering, North China Electric Power University \\ Baoding 071003, Hebei Province, China \\ E-mail: liuyingpei_123@126.com
}

\begin{abstract}
A coordinated grid-connected control strategy for PV batteryenergy storage hybrid power system with electric vehicle is proposed. PV, energy storage and electric vehicle models are built respectively. The front stage DC/DC converter of PV system utilizes maximum power point tracking control, and the bidirectional $\mathrm{DC} / \mathrm{DC}$ is used for energy storage system and electric vehicle to keep DC voltage stable. The after stage DC/AC parallel inverters of the PV battery-energy storage hybrid power system with electric vehicle adopt constant DC voltage and constant reactive power control. The constant current and constant voltage control is adopted when electric vehicle is charged. The proposed control strategy is simulated by Simulink simulation platform, the simulation results are analyzed to verify the feasibility and effectiveness of the proposed control strategy.
\end{abstract}

Key words: PV battery energy storage hybrid power system, electric vehicle and grid connected control

\section{Introduction}

With the development of distributed generation (DG) and microgrid, the scale of photovoltaic power generation is gradually expanding [1-2]. However, due to the disadvantages of photovoltaic power generation such as randomness and volatility and weak reactive power support, it has a growing impact on the grid system [3-5]. Theoretical research and the practice of energy storage projects at home and abroad show that the distributed energy storage system is an effective approach to solve the power balance, stability and power quality problems of photovoltaic access system [6-7]. Electric vehicles can be controlled in time and space. Electric vehicles can be inserted into the grid to store electrical energy when the load is low and DG is sufficient, and can be connected to the grid to release energy when the load is high. Therefore, electric vehicles can be used as both micro source (V2G) and load (charging) [8]. In the future, a large number of charging and discharging equipment of electric vehicles, as well as the continuous development of the photovoltaic micro-grid, will inevitably impact the grid in different degrees [9]. Therefore, it is particularly important to study the parallel inverters gridconnected control of PV battery-energy storage hybrid power system with electric vehicle.

In this paper, the control strategy of the parallel inverters for the PV battery-energy storage hybrid power system with electric vehicle is studied. PV adopts maximum power point track-
ing(MPPT) control, the parallel inverters adopt constant DC voltage and constant reactive power control, and the constant voltage and constant current control strategy is adopted when electric vehicle is charged. The proposed control strategy is simulated by Simulink simulation platform, the simulation results are analyzed to verify the feasibility and effectiveness of the proposed control strategy.

\section{PV Battery-energy Storage Hybrid Power System with electric vehicle}

The structure of PV battery-energy storage hybrid power system with electric vehicle designed in this paper is shown in figure 1 , including electric vehicle system, photovoltaic power generation system, energy storage system, load and inverter control system of each system.

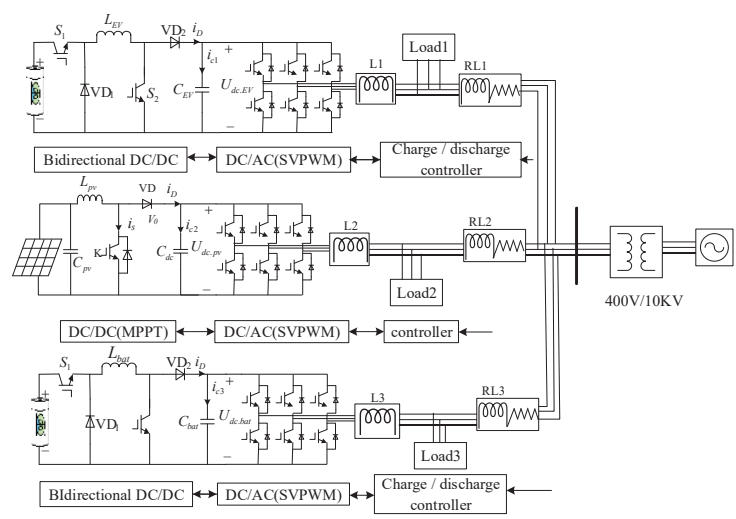

Fig. 1 Structure of PV battery-energy storage hybrid power system with electric vehicle

(1) The photovoltaic power generation system is mainly composed of front stage unidirectional DC/DC and after stage $\mathrm{DC} / \mathrm{AC}$. The MPPT is realized by using the disturbance observation method in the front stage. (2)The energy storage system is composed of bidirectional DC/DC and DC/AC. It is charged and discharged according to the instruction of inverter control. (3) The charging and discharging of electric vehicle is controlled mainly according to the charging and discharging control command under the condition of grid-connection operation, which includes the buck chopper and inverter. Electric vehicles can be used as micro source (V2G) and load by charging and discharging control switch. (4) There are two types of DC/DC converter: unidirectional DC/DC and bidirectional DC/DC. Photovoltaic 
power generation can only be one-way energy flow, using oneway control output; The energy storage system and electric vehicle system should realize bidirectional energy flow and realize bilateral interaction through bidirectional control. (5) The DC/AC parallel inverters adopt constant DC voltage and constant reactive power control.

\section{Parallel Inverter control strategy}

\section{A. DC/DC Converter Control}

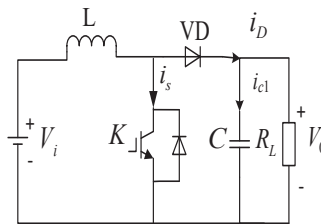

(a) Boost/Buck converter

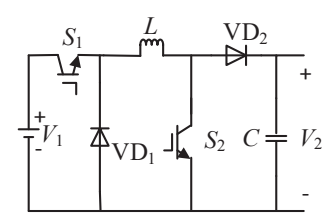

(b)Buck-Boost converter
Fig. 2 The DC/DC converter

The DC/DC converter, known as chopper.as shown in figure 2, there are two types of $\mathrm{DC} / \mathrm{DC}$ converter: unidirectional $\mathrm{DC} / \mathrm{DC}$ and bidirectional DC/DC. DC/DC topology diagram circuit mainly consists of inductance, capacitance, IGBT switching device $\mathrm{K}$ (S1, S2) and diode VD (VD1, VD2).

Both unidirectional DC/DC and bidirectional DC/DC adjust the duty cycle ratio by controlling the openning and closing of both IGBT, so as to achieve the control of input voltage or input and output voltage. PV adopts unidirectional DC/DC and Boost converter topology as shown in figure 2 (a). The duty ratio of switch $\mathrm{K}$ in the control circuit is used to control the input voltage. The energy storage and electric vehicle use bidirectional DC/DC control. The buck-boost converter, as shown in figure 2 (b), through the PWM control of its conduction ratio to achieve its switching on and off, and then control the output voltage. The duty ratio of the two switch tubes are set as D1, D2, V1 and V2, respectively, as shown in formula 1.

$$
\frac{V_{1}}{V_{2}}=\frac{1-D_{2}}{D_{1}}
$$

\section{B. Maximum Power Point Tracking Control}

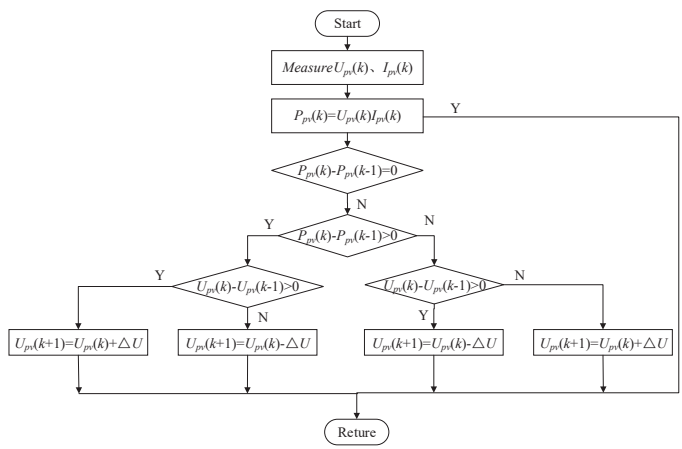

Fig. 3 Flow chart of disturbance observation method
Maximum power point tracking (MPPT) refers to the maximum power output in all situations. In this paper, the disturbance observation method is the most commonly used by photovoltaic power generation system. By referring to a self-optimizing search program, as shown in figure 3, the constant step length disturbance is added to the PV output voltage, and the change of current and pre-change power is compared in real time, so that PV array can work at the maximum power point as far as possible.

\section{DC/AC Grid Converter Control}

As shown in figure 4, the parallel inverters in this paper adopt double loop control, the outer loop is DC voltage/reactive power control, and the inner loop is current control. Where $U_{\text {q.ref }}$ and $U_{\text {d.ref }}$ are the instructions value of $\mathrm{d}$ and $\mathrm{q}$ axis components of the grid side voltage. The output voltage actual value of the unidirectional DC/DC converter $U_{d c}$ and the network side reactive power actual value $Q$ are the input of outer ring value of the grid inverter control system, compared respectively with DC voltage instruction value $U_{d c \text { ref }}$ and network side reactive power instruction value $Q_{\text {ref. }}$ The input current instruction value $I_{\text {q.ref }}$ and $I_{\text {d.ref }}$ are obtained through the outer loop PI controller for synchronous rotating coordinate system under the current inner loop controller. After coordinate transformation, the $\mathrm{d}, \mathrm{q}$ components of the grid side DC current $I_{d}$ and $I_{q}$ are obtained, and they compared with their instruction value of corresponding current $\mathrm{d}$ and $\mathrm{q}$ component $I_{\text {q.ref }}$ and $I_{\text {d.ref }}$. The 6 PWM trigger pulses are obtained through the inner loop PI controller and PWM modulation. Finally, IGBT is controlled to realize non-static adjustment of constant DC voltage/ constant reactive power.

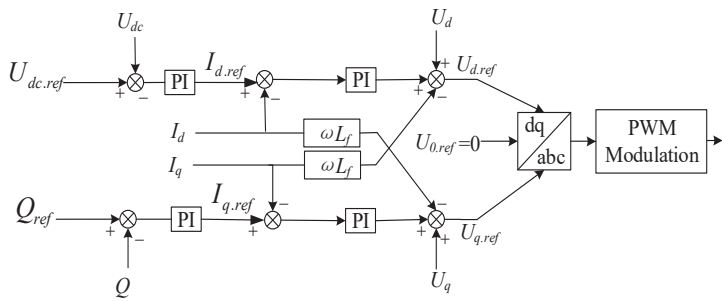

Fig. 4 Structure of inverter Control

\section{Constant Voltage and Constant Current Charging Control Strategy}

The above mentioned is the control strategy of electric vehicle is the micro source (V2G) of the grid. When electric vehicle is used as system load, the constant voltage and constant current charging control strategy is adopted. The control strategy is shown in table 1.

TABLE I

CONTROL MODEC OF HARGING MACHINE

\begin{tabular}{|c|c|c|c|}
\hline EV & $\mathrm{AC} / \mathrm{DC}$ part & $\mathrm{DC} / \mathrm{D}$ & part \\
\hline $\begin{array}{c}\text { Control } \\
\text { mode }\end{array}$ & $\begin{array}{lc}\text { Inverter } & \text { Constant } \\
& \text { DC voltage }\end{array}$ & Converter & $\begin{array}{l}\text { Constant current } \\
\text { constant voltage }\end{array}$ \\
\hline
\end{tabular}

The current loop PI control is adopted in the constant current stage. By changing the duty cycle ratio, the on-off of the switch tube is controlled and the output current is kept constant. The control structure of inverter is shown in figure 5 . 


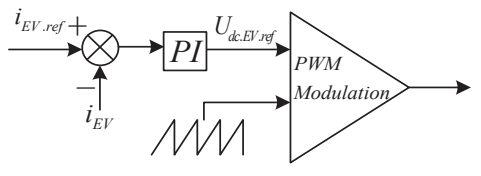

Fig. 5 Structure of constant current control

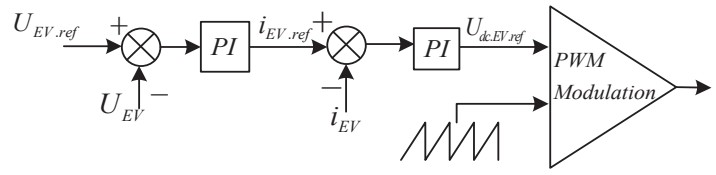

Fig. 6 Structure of constant voltage control

Constant voltage control adopts double closed loop control of external power battery terminal voltage and internal inductance current. The function of current inner loop is to conduct current control according to the current instruction output by the voltage of the outer loop, and improve the dynamic response of the system. The outer voltage loop is used to maintain the stability of the power battery terminal voltage. The structure of inverter control shown as figure 6.

\section{Simulation and Discussion}

In order to verify the effectiveness of the control strategy in this paper, a simulation study is carried out. In this paper, a complete simulation structure diagram of the PV battery-energy system with electric vehicles was built under the Simulink software environment. The simulation parameters are:

1.The DC voltage of the PV is $800 \mathrm{~V}$, the sampling frequency is $1000 \mathrm{kHZ}$, the Boost circuit capacitance is $60 \mathrm{e}^{3} \mathrm{uF}$, the Boost circuit inductance is $50 \mathrm{e}^{-3} \mathrm{mh}$, the DC capacitor is $750 \mathrm{uF}$, and the converter reactor is $1 \mathrm{Mh}$, and constant reactive power of $\mathrm{PV}$ is 10000Var.

2. The rated voltage of energy storage battery is $400 \mathrm{~V}$, the rated capacity is $200 \mathrm{Ah}$, and the initial charging state of battery is $50 \%$, charge-discharge current is $\pm 110 \mathrm{~A}$, constant DC voltage is $800 \mathrm{~V}$, and its constant reactive power is 20000 Var.

3.The electric vehicle battery parameters are same as the energy storage battery when it is discharged. The constant DC voltage is $800 \mathrm{~V}$, and the constant reactive power is 0 Var. When it's charged, the current of constant current charging is $-110 \mathrm{~A}$ and voltage of constant voltage charging is $440 \mathrm{~V}$.

4.Load1, Load2 and Load3 are set as $0.02 \mathrm{MW}+0.02 \mathrm{Mvar}$.

\section{A. Example 1, Electric Vehicle Discharge}

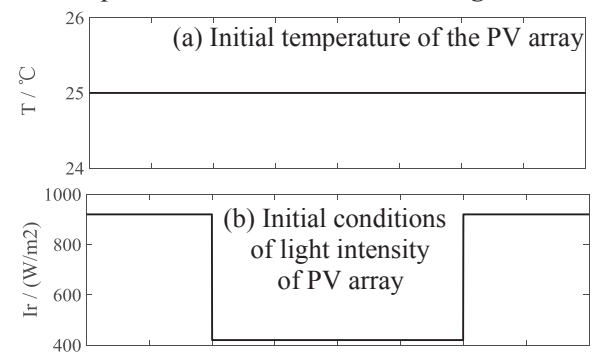

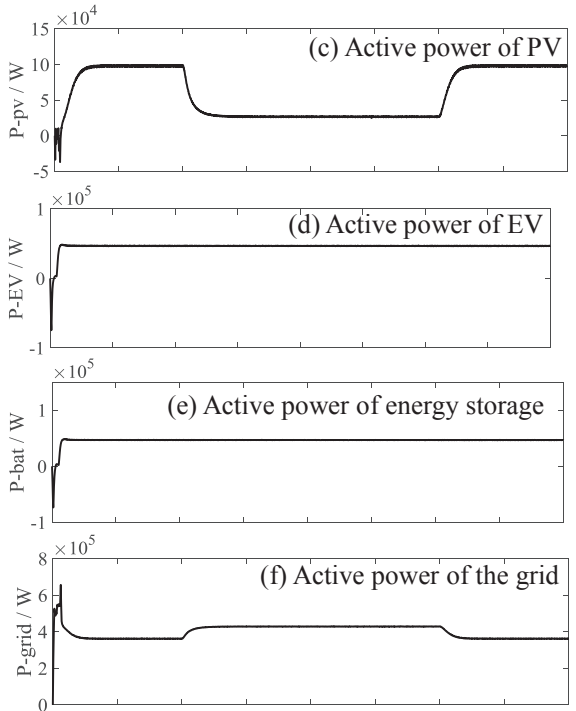
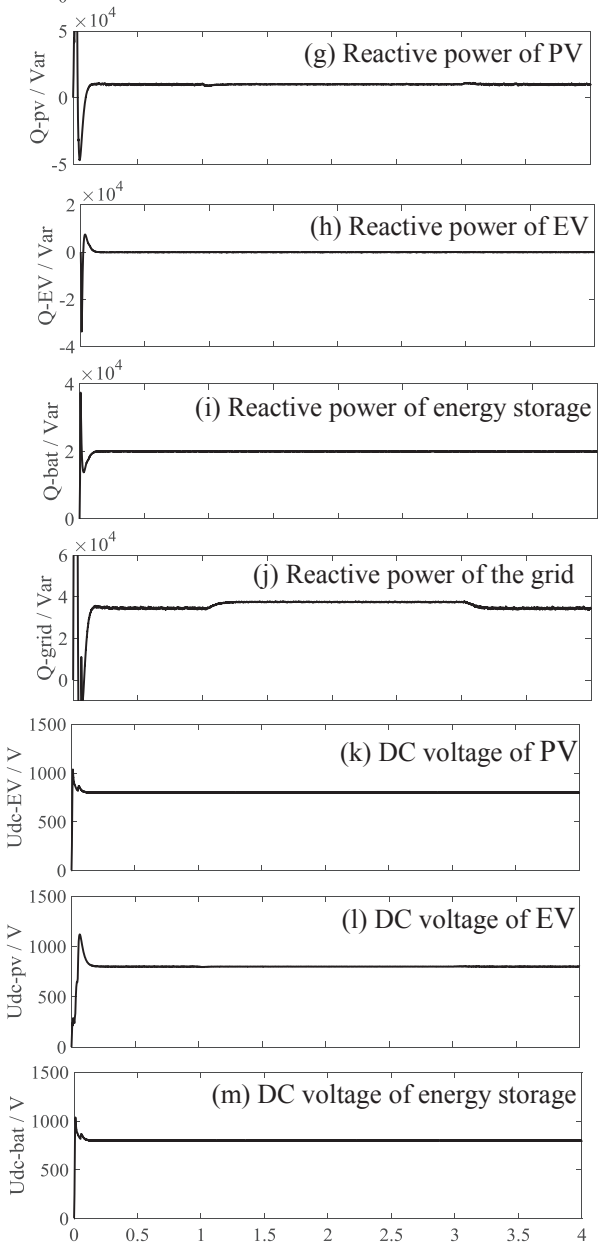

Fig. 7 Simulation results of example 1 
Figure 7 shows the simulation results of example 1, where (ab) is the initial condition of the temperature and light intensity of $\mathrm{PV}$ array, and (c-f) are the active power of PV, electric vehicle, energy storage and the grid, while (g-j) are respectively reactive power of them. Figure.7 (k-m) are the DC voltage of PV, electric vehicle and energy storage system.

It can be seen from the simulation figure that the PV can achieve MPPT under the control of DC/DC, and the active power of PV changes steadily, reducing the impact on the system. Since charging current is constant in energy storage and EV systems, their active power is constant. The active power generated by the grid makes up for the demand of active power load. The reactive power load of the system is $0.06 \mathrm{MVar}$, the reactive power of the $\mathrm{PV}$ system is stable at the instruction value of $0.01 \mathrm{MVar}$, the reactive power of the energy storage system is about $0.02 \mathrm{MVar}$, and the electric vehicle is 0Mvar. Therefore, the grid system bears other reactive loads as shown in figure 7 (j). The DC voltage of distributed generation are shown in figure $7(\mathrm{k}-\mathrm{m})$, which are stable at the instruction value of $800 \mathrm{~V}$. In summary, the proposed control strategy of constant voltage/constant reactive power is effective.

\section{B.Example 2, Electric Vehicle Charge}
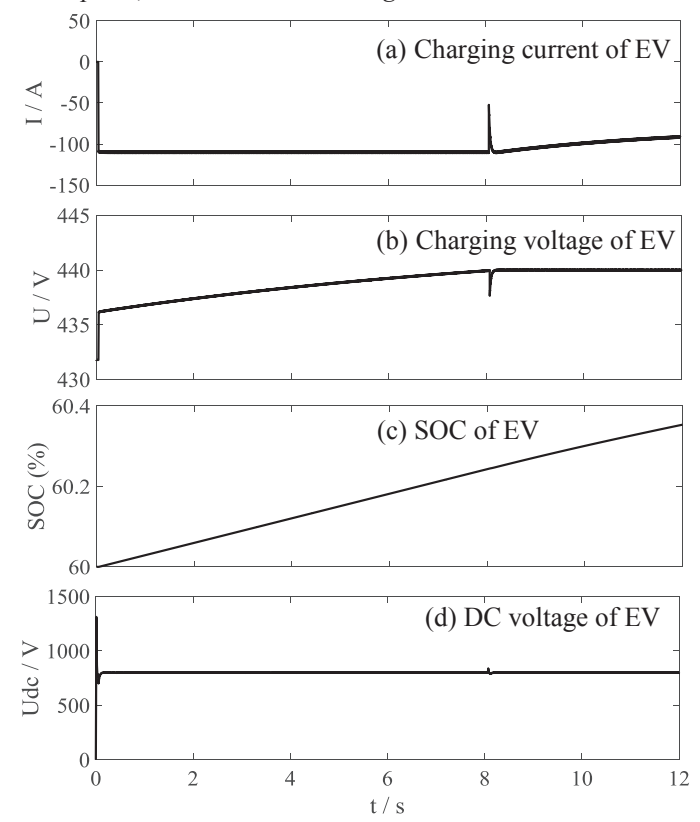

Fig. 8 Simulation results of example 2

As shown in figure. 8 , the simulation results of electric vehicle when it is load of the grid. The constant current and voltage are given when electric vehicle.is charged, the current of constant current charging is-110A, the voltage of constant voltage charging is $440 \mathrm{~V}$.

It can be seen from figure $8(a-b)$ that the charging mode is constant current at the beginning stage, and the constant current is $110 \mathrm{~A}$. With the deepening of charging, the battery voltage gradually increases to $440 \mathrm{~V}$, then the charging machine is switched to the constant voltage charging mode, the constant current charging time is $8 \mathrm{~s}$. Then, the terminal voltage of the power battery remains at $440 \mathrm{~V}$. At this time, the charging current gradually decreases and enters the trickling charging stage, so as to continue to charge the battery.

It can be seen from figure 8 (c-d) that the charge capacity of the power battery increases faster in the constant current stage, while the charge capacity increases slowly in the constant voltage stage due to the reduction of charging current. The intermediate voltage of $\mathrm{AC} / \mathrm{DC}$ inverter remains stable after charging, which verifies the effectiveness of the control strategy of constant voltage and constant current charging of power battery.

\section{Conclusion}

In this paper, a control strategy for PV battery-energy storage hybrid power system with electric vehicle has been proposed. The PV, energy storage and electric vehicle models were established respectively by using Simlink, and the parallel inverters control was adopted. Through the establishment of simulation, it is found that the PV system can achieve the MPPT, the inverter can achieve the constant DC voltage/constant reactive power control, and the constant voltage constant current control can be realized when the electric vehicle is charged. The simulation results verify the effectiveness of this strategy.

\section{References}

[1] G.M.Shafiullah, et al, "Experimental and simulation study of the impact of increased photovoltaic integration with the grid", Journal of Renewable \& Sustainable Energy, 6( 3), pp. 1-20, December 2014.

[2] Ming Ding, et al, "A review of the influence of large-scale photovoltaic power generation on power system", Proceedings of the CSEE, 34(01), pp. 1-14, January 2014.

[3] CuiPing Li, et al, "A Survey of Large-Scale distributed Control methods for reactive Power and Voltage in Grid-connected Photovoltaic Systems", Journal of Northeast University of Electric Power, 37(02), pp. 82-88, April 2017.

[4] Qiong Tao, et al, "Multiple data sources fusion and distributed photovoltaic grid-connected admission analysis method considering energy storage configuration mode", High Voltage Technology, 44 (04), pp. 1093-1098, February 2018.

[5] Lingling Sun, et al, "Research on access capacity of distributed photovoltaic power generation based on voltage deviation opportunity constraint", Journal of Electrotechnical Science and Technology, 33 (07), pp. 1560-1569, December 2018.

[6] Haijing Yang, et al, "Application and Analysis of distributed Energy Storage in Power system", Management Technology of Electric Appliances and Energy efficiency, (03), pp. 47-52, February 2018.

[7] Wei Ma, et al, "Coordinated complementary power fluctuation strategy and economic analysis of optical storage", Power Grid Technology., 42 (03), pp. 730-737, February 2018.

[8] Mahmoud Shepero, et al, "Modeling of photovoltaic power generation and electric vehicles charging on city-scale: A review", Renewable and Sustainable Energy Reviews, 89, pp.62-71, February 2018

[9] Jianguo Yao, et al, "The concept and Research Framework of SourceNetwork-load Interactive Operation Control for Smart Grid", Power system Automation, 36 (21), pp. 1-6+12, November 2012 